\title{
Studies on the Anticandidal Mode of Action of Allium sativum (Garlic)
}

\author{
By MAHMOUD A. GHANNOUM \\ Department of Botany and Microbiology, Faculty of Science, Kuwait University, \\ PO Box 5969 Safat, 13060 Kuwait
}

(Received 16 May 1988; revised 19 July 1988)

The mode of action of aqueous garlic extract (AGE) was studied in Candida albicans. The minimum inhibitory concentration (MIC) of AGE against six clinical yeast isolates ranged between 0.8 and $1.6 \mathrm{mg} \mathrm{ml}^{-1}$. Scanning electron microscopy and cell leakage studies showed that garlic treatment affected the structure and integrity of the outer surface of the yeast cells. Growth of $C$. albicans in the presence of AGE affected the yeast lipid in a number of ways: the total lipid content was decreased; garlic-grown yeasts had a higher level of phosphatidylserines and a lower level of phosphatidylcholines; in addition to free sterols and sterol esters, C. albicans accumulated esterified steryl glycosides; the concentration of palmitic acid $(16: 0)$ and oleic acid $(18: 1)$ increased and that of linoleic acid $(18: 2)$ and linolenic acid $(18: 3)$ decreased. Oxygen consumption of AGE-treated $C$. albicans was also reduced. The anticandidal activity of AGE was antagonized by thiols such as L-cysteine, glutathione and 2-mercaptoethanol. Interaction studies between AGE and thiols included growth antagonism, enzymic inhibition and interference of two linear zones of inhibition. All three approaches suggest that AGE exerts its effect by the oxidation of thiol groups present in the essential proteins, causing inactivation of enzymes and subsequent microbial growth inhibition.

\section{INTRODUCTION}

Garlic (Allium sativum) has been used as a spice, food and folk medicine since ancient times (Block, 1985). Investigations have been undertaken to provide a scientific basis for its medicinal use and several have reported its medicinal, insecticidal, antimicrobial, antiprotozoal and antitumour properties (Adetumbi et al., 1986; Moore \& Atkins, 1977). In addition, garlic extract has been reported to possess an in vitro growth inhibition effect against a large number of fungi including yeasts (Appleton \& Tansey, 1975; Barone \& Tansey, 1977) and to have a protective effect against in vivo experimental fungal infections (Prasad et al., 1982). Kabelik (1970) demonstrated that garlic extract was more effective against pathogenic yeasts, especially Candida albicans, than nystatin, gentian violet or methylene blue. Prasad \& Sharma (1980) showed that garlic treatment in feed protected chicks from experimental candidosis and that infection induced by oral inoculation of chicks with $C$. albicans was successfully cured by providing a ration containing $5 \%$ garlic.

The chemical composition of garlic has been defined (Block, 1985) and its active component is thought to be a sulphur-containing compound known as allicin (Cavillito et al., 1944). The mechanism of action of garlic is unknown, but Barone \& Tansey (1977) proposed that garlic acts by inactivating essential thiols. Adetumbi et al. (1986) proposed that blockage of lipid synthesis is likely to be an important feature of the anticandidal activity of garlic. This paper reports some studies to elucidate the mode of action of garlic.

\footnotetext{
Abbreviations: AGE, aqueous garlic extract; SEM, scanning electron microscopy; CTAB,
} hexadecyltrimethylammonium bromide; $\mathrm{ADH}$, alcohol dehydrogenase. 


\section{METHODS}

Yeast. Three species of Candida were used in the present study: C. albicans, C. tropicalis, and C. pseudotropicalis. Three strains of the first species were investigated: $C$. albicans ATCC 10231 (isolated from bronchomycosis) was obtained as a lyophilized culture. The other two C. albicans strains (KCCC 14172 and KCCC 13878), as well as $C$. tropicalis KCCC 13605 and C. pseudotropicalis KCCC 13709, were obtained from the oral cavity of patients undergoing radiotherapy. All cultures were routinely maintained on modified Sabouraud dextrose agar (Difco).

Preparation of aqueous garlic extract $(A G E)$. Fresh AGE was prepared according to a modification of the procedure used by Moore and Atkins (1977). Fresh garlic cloves $(10 \mathrm{~g})$ were hulled, minced, ground and blended at high speed for 5-7 min in $100 \mathrm{ml}$ Yeast Nitrogen Base (Difco) supplemented with $2.5 \%(\mathrm{w} / \mathrm{v})$ glucose (YNBG) and adjusted to $\mathrm{pH} 6.0$. The pulp was centrifuged at $8000 \mathrm{~g}$ for $20 \mathrm{~min}$. The supernatant was decanted and centrifuged at $12000 \mathrm{~g}$ for $20 \mathrm{~min}$ to remove insoluble particles. The re-centrifuged supernatant was sterilized by filtration.

The garlic extract was maintained at $25^{\circ} \mathrm{C}$ during preparation. Dry matter composition of the extract was determined by drying triplicate $10 \mathrm{ml}$ samples to a constant weight at $105^{\circ} \mathrm{C}$. This yielded $1.2 \pm 0.05 \mathrm{~g} \mathrm{AGE}$ per $10 \mathrm{~g}$ fresh garlic. The fresh garlic was used immediately following extraction.

Minimum inhibitory concentrations (MICs). These were determined by a broth dilution technique. Serial twofold dilutions of AGE were prepared in triplicate in sterile YNBG ( $5 \mathrm{ml}$ volumes). To each tube, $0 \cdot 1 \mathrm{ml}$ of an overnight culture of various yeasts was added, and the tubes were then incubated for $24 \mathrm{~h}$ at $37^{\circ} \mathrm{C}$. The control tubes contained no AGE.

Effect on growth. An inoculum of C. albicans $\mathrm{KCCC} 14172$ was grown overnight at $37^{\circ} \mathrm{C}$ with rotary agitation (160 r.p.m.) in YNBG. Cells were centrifuged and used to inoculate $100 \mathrm{ml}$ fresh medium, with or without AGE. Samples were taken at intervals and the growth rate was followed by measuring the optical density at $420 \mathrm{~nm}$.

Antagonism of inhibition was followed by adding either glutathione or 2-mercaptoethanol (1 mM) to flasks containing $0.8 \mathrm{mg} \mathrm{AGE} \mathrm{ml}^{-1}$ and measuring the growth rate as above.

Measurement of leakage of intracellular material. Equal volumes $(5 \mathrm{ml})$ of AGE and of cell suspension were mixed to give a final cell concentration of $1 \mathrm{mg} \mathrm{ml}^{-1}$. After intervals at $24^{\circ} \mathrm{C}$, the cells were removed by centrifugation $(7000 \mathrm{~g}, 5 \mathrm{~min})$. Cellular exudates were determined by direct spectrophotometric measurement of the material absorbing at $260 \mathrm{~nm}$ in the supernatant. The blank consisted of yeast cell suspension treated in the same manner without the addition of AGE.

Scanning electron microscopy (SEM). C. albicans was grown in flasks containing $100 \mathrm{ml} \mathrm{YNBG}$ with and without AGE in shake culture at $37^{\circ} \mathrm{C}$ for $24 \mathrm{~h}$. Cells were then prepared for SEM and coated with gold-palladium alloy (Ghannoum et al., 1986 b). Samples were examined in a stereoscan Electron Microscope (Novoscan 30) at an angle of $45^{\circ}$.

Effect on oxygen consumption. The uptake of oxygen was determined using a Rank-type oxygen electrode following the method of Estrabrook (1967). Yeast cells were suspended in a $0.5 \mathrm{M}$-phosphate buffer, $\mathrm{pH} 7 \cdot 2$, with $0.8 \mathrm{mg} \mathrm{ml}^{-1} \mathrm{AGE}$ and without $\mathrm{AGE}$, and oxygen consumption ( $\mu \mathrm{mol} \mathrm{O}_{2} \mathrm{~h}^{-1}$ per $10^{7}$ cells) was measured. Another experiment was done after incorporating glucose $(2.5 \%, \mathrm{w} / \mathrm{v})$ in the assay medium.

Effect on lipid composition. Yeast cells grown as a shake culture at $37^{\circ} \mathrm{C}$ for $3 \mathrm{~d}$, in YNBG with $0.4 \mathrm{mg} \mathrm{AGE} \mathrm{ml}-1$ ( $0.5 \mathrm{MIC})$ and without AGE, were used. Total lipid was extracted with chloroform/methanol, $2: 1(\mathrm{v} / \mathrm{v})$ three times and purified by established procedures (Folch et al., 1957). The extract was analysed by thin layer chromatography (TLC) on plates of silica gel $(0.25 \mathrm{~mm}$ thickness). Apolar compounds were resolved by the solvent system hexane/diethyl ether/acetic acid $(90: 10: 1$, by vol.) (Mangold \& Malins, 1960). Polar lipids were analysed by twodimensional chromatography using chloroform/methanol/7 M-ammonium hydroxide $(65: 25: 4$, by vol.) in the first direction and chloroform/methanol/acetic acid/water $(170: 25: 25: 4$, by vol.), in the second direction (Nichols, 1964). The spots were visualized with iodine vapour or by charring at $220^{\circ} \mathrm{C}$ after spraying with $50 \%$ $\mathrm{H}_{2} \mathrm{SO}_{4}$. Individual classes were identified by comparing their chromatographic behaviour with that of authentic samples and by using specific spray reagents (Dittmer \& Lester, 1964; Siakotos \& Rouser, 1965; Stahl, 1962).

The identity of phospholipid fractions isolated by preparative TLC was confirmed by the analysis of their partial degradation products (Dawson, 1984). The IR spectra of fractions were recorded using a Perkin-Elmer 398 IR-Spectrophotometer and compared with the spectra of authentic samples. Lipid fractions resolved by twodimensional chromatography were quantitatively determined by gas chromatographic analysis of their acyl moieties using heptadecanoic acid as an internal standard (Radwan, 1978). After methanolysis of total lipids (Chalvardjian, 1964), the resulting methyl esters were purified by TLC and analysed by gas chromatography using a Pye-Unicam 204 chromatograph fitted with a glass column, $1.83 \mathrm{~m} \times 4 \mathrm{~mm}$, i.d., packed with $15 \%$ (w/w) DEGS on Anakrom D, 100-120 mesh, at a temperature of $180^{\circ} \mathrm{C}$ with nitrogen as the carrier gas.

Effect of thiol-containing compounds on AGE activity. The effect of possible antagonists on AGE action was examined by a technique which utilized the interference of two linear zones of inhibition (Maccacaro, 1961). One filter paper strip soaked in $10 \mathrm{ml} \mathrm{AGE}$, at a concentration of $0.8 \mathrm{mg} \mathrm{ml}^{-1}$, was placed on a Sabouraud dextrose agar plate seeded with $C$. albicans KCCC 14172. A second strip, soaked with glutathione, L-cysteine, 2mercaptoethanol, mercuric chloride or hexadecyltrimethylammonium bromide (CTAB) (all at $1 \mathrm{mM}$ ), was placed 
at a right angle to the first strip, with ends overlapping. For control experiments the second strip was soaked with distilled water. The plates were incubated at $37^{\circ} \mathrm{C}$ for $24 \mathrm{~h}$ and the effect of each of the above compounds on the zone of inhibition produced by AGE was noted.

Effect on enzyme activity. Trypsin was assayed for caseinolytic activity by the method of Kunitz (1947). Papain activity was determined by digestion of casein at $\mathrm{pH} 8.0$ by the method of Kunitz as modified for papain (Arnon \& Shapira, 1967). This method is based upon the release of trichloroacetic-acid-soluble peptides from casein (measured by absorbance at $280 \mathrm{~nm}$ ). Yeast alcohol dehydrogenase (ADH) activity was determined by the method of Racker (1955) by monitoring the production of NADH spectrophotometrically at $340 \mathrm{~nm}$. AGE was prepared by extracting fresh garlic with $0.9 \%$ saline instead of YNBG and samples of this extract $(0 \cdot 1-0 \cdot 2 \mu l)$ were preincubated with the test enzymes for 5 or $15 \mathrm{~min}$ at room temperature before assay for enzyme activity. Final enzyme concentrations were 22,13 and $1 \cdot 1 \mu \mathrm{g} \mathrm{m}^{-1}$ for trypsin, papain and ADH, respectively.

\section{RESULTS}

Effect of $A G E$ on growth, morphology and oxygen consumption

The MIC values of AGE for six yeast isolates ranged between 0.8 and $1.6 \mathrm{mg} \mathrm{ml}^{-1}$. Fig. 1 shows the effect of AGE on the growth rate of C.albicans KCCC 14172. Concentrations of AGE below the MIC value (for example 0.25 MIC) caused retardation of growth. The loss of intracellular constituents, as measured by the estimation of material absorbing at $260 \mathrm{~nm}$, was observed with $C$. albicans KCCC 14172 . Leakage occurred at an initially rapid rate within the first 5-10 min of contact. Subsequently an almost constant value was reached.

The morphology of $C$. albicans KCCC 14172 grown in shake culture at $37^{\circ} \mathrm{C}$ for $24 \mathrm{~h}$ in the presence $\left(0.4 \mathrm{mg} \mathrm{m}^{-1}\right)$ or absence of AGE was compared by SEM (Fig. 2). Control cells of $C$. albicans were generally smooth-walled bodies, spherical to elongated in shape (Fig. 2a). Cells grown in the presence of AGE appeared deformed and distorted; cell collapse and cytoplasmic debris were observed (Fig. $2 b$ ). No pseudohyphal formation was noticed at the MIC or in control tubes containing YNBG only; however, pseudohyphae formed at concentrations below the MIC.

AGE $\left(0.8 \mathrm{mg} \mathrm{m}^{-1}\right)$ reduced the oxygen consumption of $C$. albicans $\mathrm{KCCC} 14172$ by $18 \%$ when compared with the control. The response to AGE was similar when glucose $(2.5 \%)$ was included in the assay mixture.

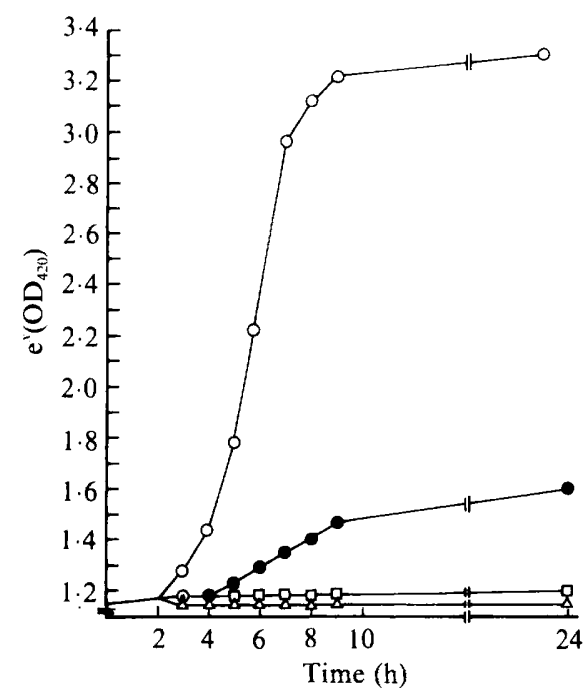

Fig. 1. Effect of AGE on shake cultures of $C$. albicans grown in $\mathrm{YNBG}$ at $37^{\circ} \mathrm{C}, \mathrm{pH}$ 6. Concentrations of AGE used (mg ml-1): $0(O) ; 0.4(O) ; 0.8(\square)$; and $1.6(\triangle)$. 

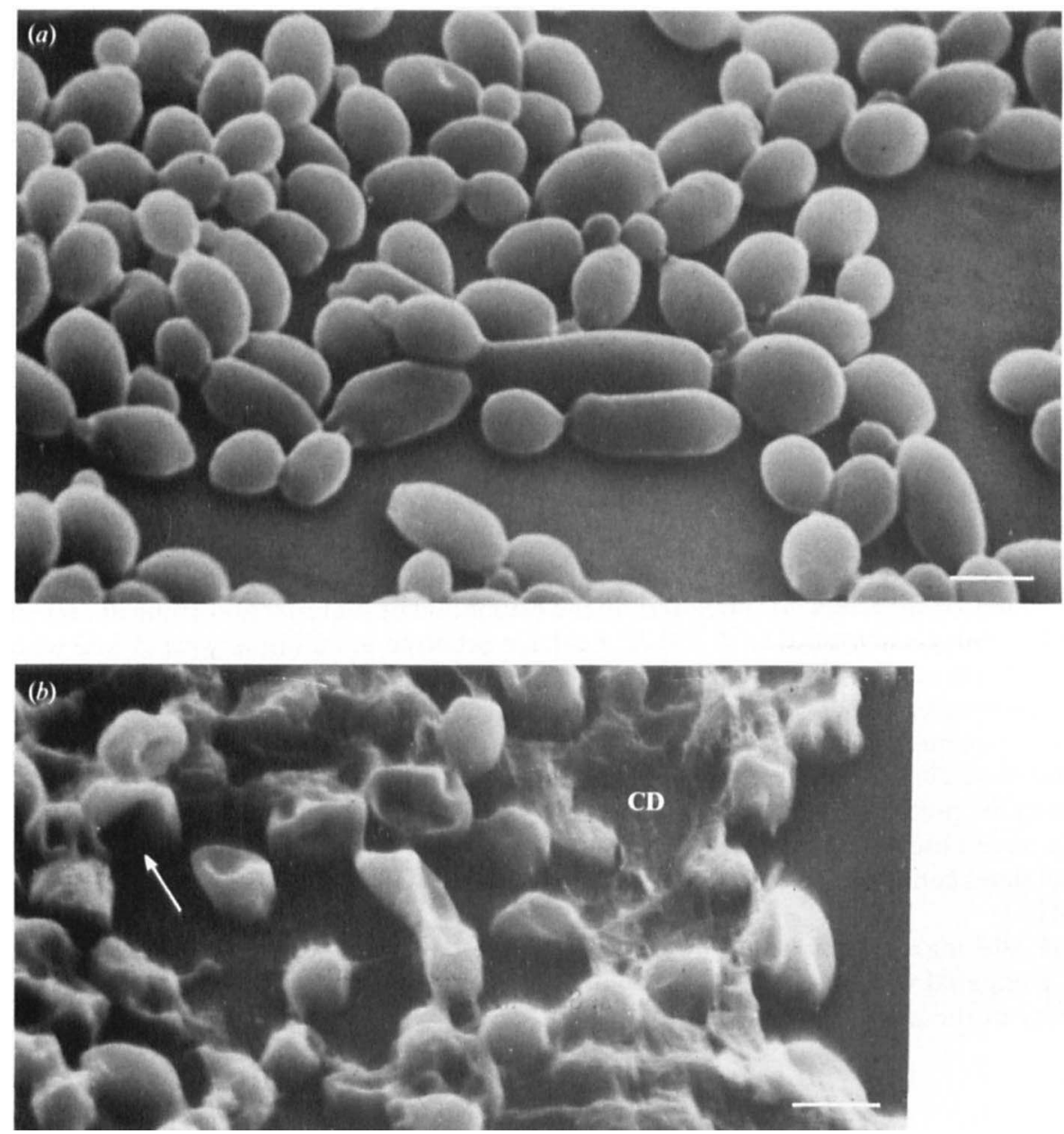

Fig. 2. SEM of C. albicans KCCC 14172 grown in the absence (a) or presence (b) of AGE. Arrow points to cell collapse; $\mathrm{CD}$, cytoplasmic debris. Bars, $4 \mu \mathrm{m}$.

\section{Effect of AGE on lipid composition}

The total lipid content of $C$. albicans grown in the presence ( $0.5 \mathrm{MIC})$ and absence of AGE was $0.4 \pm 0.02 \%$ and $1.04 \pm 0.03 \%$, (mean \pm SD) respectively, on a dry weight basis. The lipids from AGE-grown C. albicans and control yeasts consisted predominantly of polar compounds (Table 1) with non-polar lipids comprising between 30 and $35.5 \%$ of the total lipid content of AGE-grown cells and control cells, respectively. Sterols in the apolar lipid fractions of controlgrown yeasts existed predominantly as steryl esters with lower proportions of free sterols; no esterified steryl glycosides were detected. In contrast, AGE-grown cells had approximately equal amounts of sterol esters, free sterols and esterified steryl glycosides. The polar lipids of both AGE-grown and control cells consisted mainly of phospholipids in addition to smaller proportions of glycolipids. C. albicans grown in the presence of AGE accumulated higher proportions of glycolipids. The major phospholipids were phosphatidylcholines, phosphatidylethanolamines, phosphatidylserines and phosphatidylinositols. Smaller proportions of phosphatidylglycerols (mainly in control C. albicans) and phosphatidic acids were also found. Higher proportions of phosphatidylserines and lower proportions of phosphatidylcholines were found in yeasts grown in the presence of AGE when compared with control C. albicans. The glycolipids were only minor constituents of the control-grown yeast lipids and were mainly ceramide 
Table 1. Comparison of lipids from C. albicans KCCC 14172 grown in the presence or absence of $A G E$

Values are expressed as the percentage $(w / w)$ of the total amount of lipid and are the means \pm SD of three determinations.

\begin{tabular}{|c|c|c|}
\hline \multirow[b]{2}{*}{ Lipids } & \multicolumn{2}{|c|}{ Relative amount $(\%, w / w)$} \\
\hline & No added AGE & Plus AGE $\left(0.4 \mathrm{mg} \mathrm{ml}^{-1}\right)$ \\
\hline \multicolumn{3}{|l|}{ Apolar compounds } \\
\hline Steryl esters & $18 \pm 0.7$ & $7 \pm 0 \cdot 2$ \\
\hline Alkyl esters & $2 \pm 0 \cdot 1$ & $2 \pm 0.05$ \\
\hline Triacylglycerols & $5.5 \pm 0.2$ & $3 \pm 0 \cdot 1$ \\
\hline Fatty acids & $2 \pm 0$ & $1.5 \pm 0.05$ \\
\hline Diglycerides & $3 \pm 0 \cdot 1$ & $8 \pm 0 \cdot 3$ \\
\hline Sterols & $5 \pm 0.1$ & $8 \cdot 5 \pm 0.6$ \\
\hline \multicolumn{3}{|l|}{ Polar compounds } \\
\hline Esterified steryl glycosides & ND & $8 \pm 0 \cdot 7$ \\
\hline Monogalactosyldiacylglycerols & ND & $7 \pm 0.5$ \\
\hline Steryl glycosides & $1 \cdot 5 \pm 0$ & ND \\
\hline Ceramide monohexosides & $3 \pm 0 \cdot 1$ & ND \\
\hline Phosphatidylethanolamines & $11.5 \pm 0.8$ & $13 \pm 1 \cdot 1$ \\
\hline Phosphatidylglycerols & Tr. & $1.5 \pm 0.1$ \\
\hline Phosphatidylcholines & $21 \cdot 5 \pm 1 \cdot 1$ & $9 \pm 0.8$ \\
\hline Phosphatidylserines & $13 \pm 0.9$ & $19.5 \pm 1.0$ \\
\hline Phosphatidylinositols & $8 \pm 0.3$ & $7.0 \pm 0.4$ \\
\hline Phosphatidic acids & $6.5 \pm 0.4$ & $5 \pm 0.3$ \\
\hline
\end{tabular}

ND, Not detected; Tr., trace.

Table 2. Constituent fatty acids of C. albicans KCCC 14172 grown in the presence or absence of $A G E$

Values are expressed as the percentage $(w / w)$ of the total amount of lipid and are the means \pm SD of three determinations.

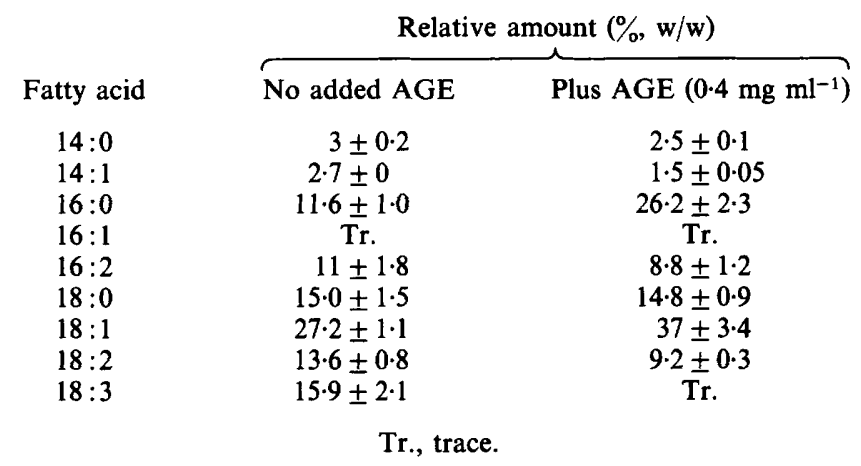

monohexosides and steryl glycosides, whereas in garlic-grown cells they were esterified steryl glycosides and monogalactosyldiacylglycerols. The fatty acid composition of C. albicans grown in the presence and absence of AGE is shown in Table 2. Yeasts grown in the presence of AGE had higher proportions of palmitic acid $(16: 0)$ and oleic acid $(18: 1)$ but lower proportions of polyunsaturated fatty acids - linoleic $(18: 2)$ and linolenic $(18: 3)$ acids - than the corresponding control yeasts.

\section{Effect of thiol-containing compounds on activity}

Screening experiments demonstrated that compounds with a thiol group were effective as neutralizing agents for AGE. Fig. 3. shows that upon addition of 2-mercaptoethanol or glutathione (1 mM each), with yeast cells grown in the presence of AGE $\left(0.8 \mathrm{mg} \mathrm{ml}^{-1}\right)$, the 


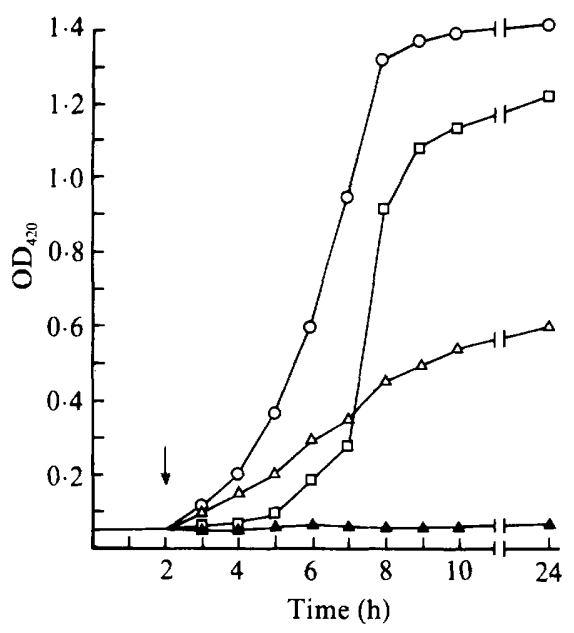

Fig. 3, Antagonism of the activity of AGE against C. albicans KCCC 14172 by thiol compounds. The arrow indicates the time of addition of the thiol compound. $O$, Control system; $\square, 0.8 \mathrm{mg} \mathrm{AGE} \mathrm{\textrm {ml } ^ { - 1 }}$ with $1 \mathrm{~mm}$-glutathione; $\triangle, 0.8 \mathrm{mg} \mathrm{AGE} \mathrm{ml}{ }^{-1}$ with $1 \mathrm{mM}-2$-mercaptoethanol; $\triangle, 0.8 \mathrm{mg} \mathrm{AGE} \mathrm{ml}^{-1}$ without thiol compounds.

growth-inhibiting action of AGE was arrested. This was confirmed by interference studies with thiol-containing compounds. Mercuric chloride did not enhance AGE activity and no interaction between AGE and CTAB was observed.

\section{Effect of $A G E$ on enzyme activity}

The effect of AGE on two enzymes with an active thiol group (papain and ADH) as compared to a proteinase with an active hydroxyl group (trypsin) was investigated. Both papain and ADH were inhibited by pre-incubation with AGE $\left(0.8 \mathrm{mg} \mathrm{ml}^{-1}\right)$ for 5 or $10 \mathrm{~min}$ : papain appearing to be more sensitive to AGE addition. Trypsin activity was not significantly inhibited by pretreatment with AGE for $10 \mathrm{~min}$.

\section{DISCUSSION}

Some authors have reported garlic to possess strong inhibitory properties for a few yeast-like fungi, others suggest that these effects are variable (Appleton \& Tansey, 1975; Tynecka \& Gos, 1973). Our results show that all the isolates of Candida spp. were sensitive to AGE with no major differences in the degree of susceptibility. The only exception was C. albicans KCCC 13878, which required double the concentration of AGE needed to inhibit other isolates. Additionally, the growth of $C$. albicans KCCC 14172 was found to be markedly inhibited by AGE.

The loss of intracellular components as well as morphological changes suggest that AGE has an effect on the yeast cell envelope. AGE caused cell collapse and damage, with sub-inhibitory concentrations leading to pseudohyphal formation. This is in agreement with the findings of Barone \& Tansey (1977).

Studies on the effect of AGE on the total lipid and fatty acid content of C. albicans showed that polar and non-polar lipids, as well as fatty acids are affected. C. albicans grown in the presence of AGE accumulated phosphatidylserines with a lower proportion of phosphatidylcholines. The principal biosynthetic pathway for phosphatidylcholines begins with the formation of phosphatidylserines from CDP-diacylglycerol and serine (Weete, 1980). Accumulation of phosphatidylserines suggests that garlic interferes with enzymes catalysing this pathway. Treatment of $C$. albicans with AGE resulted in an accumulation of palmitic acid and oleic acid with a lower proportion of linoleic acid and only traces of linolenic acid. It appears, therefore, that the blocking effect of garlic extract on lipid biosynthesis reported earlier (Adetumbi et al., 
1986) may also involve the biosynthesis of unsaturated fatty acids. Another salient point is that oxygen consumption is also reduced by garlic extract. It is well known that molecular oxygen is essential for the formation of monoenoic fatty acids in eukaryotes. Furthermore, the enzyme $\beta$ hydroxydecanoyl thioester dehydrase, catalysing the desaturation of fatty acids is a thiol enzyme (Weete, 1980). The blockage of phosphatidylcholine biosynthesis by AGE observed in this study, and its relation to fatty acid desaturation known to occur in fungi (Chavant et al., 1978; Kates and Paradis, 1973), may explain the lower proportion of linoleic acid and linolenic acid found in this investigation. The accumulation of esterified steryl glycosides in C. albicans upon garlic treatment is interesting. This class of glycolipid has not been fully explored in fungi (Weete, 1980), and there is evidence of sterol glycosylation in yeast (Parks et al., 1978). However, the biological role(s) of this class of compounds is still unknown. The possibility that steryl glycosides may confer more rigidity on membranes than free sterols has been suggested (Ghannoum et al., 1986a). However, relevance of garlic treatment to the accumulation of esterified steryl glycosides requires further investigation.

The antagonism of the anticandidal activity by thiol compounds suggests that AGE exerts its effect by inactivating thiol groups present in the essential proteins of $C$. albicans. This is supported by our results which involve growth antagonism, interference in the linear zone of inhibition and enzymic inhibition. All three approaches support this hypothesis and confirm the findings of earlier investigators (Barone \& Tansey, 1977).

The author would like to thank Miss L. Khamis, and Messrs K. Abu-Elteen and S. Rajendra for their excellent technical assistance. Thanks are also due to Drs N. Sorkhoh, W.R. Bowman, M. Thomson and Professor S.S. Radwan for their support and encouragement. This investigation was supported by Kuwait University, Research Council, Grant no. SO-031.

\section{REFERENCES}

Adetumbi, M., Javor, G. T. \& LAU, B. H. S. (1986). Allium sativum (garlic) inhibits lipid synthesis by Candida albicans. Antimicrobial Agents and Chemotherapy 30, 499-501.

APPLETON, J. A. \& TANSEY, M. R. (1975). Inhibition of growth of zoopathogenic fungi by garlic extract. Mycologia 67, 882-885.

ARnon, R. \& Shapira, E. (1967). Antibodies to papains, a selective fractionation according to inhibitory capacity. Biochemistry 6, 3942-3950.

Barone, F. E. \& TANSEY, M. R. (1977). Isolation, purification, identification, synthesis, and kinetics of activity of the anticandidal component of Allium sativum, and a hypothesis for its mode of action. Mycologia 69, 793-825.

BLOCK, E. (1985). The chemistry of garlic and onions. Scientific American 252, 114-119.

Cavillito, C. J., Buck, J. S. \& Suter, C. M. (1944). Allicin, the antibacterial principle of Allium sativum. II. Determination of the chemical structure. Journal of the American Chemical Society 66, 1952-1954.

Chalvardian, A. (1964). Fatty acids of brown and yellow fat in rats. Biochemistry Journal 90, 518-521.

Chavant, L., Mazliak, P. \& Sancholle, M. (1978). Unsaturated fatty acid biosynthesis by the mold Aspergillus ochraceus. Physiologie Vegetale 16, 607-616.

Dawson, R. M. C. (1984). Products of partial degradation of phospholipids. In Handbook of Chromatography. Lipids, vol. 1, p. 545. Edited by G. Zweig, J. Sherma and H. K. Mangold. Boca Raton, Florida: CRC.

DitTMER, J. C. \& LeSTER, R. L. (1964). A simple specific spray for the detection of phospholipids on thin-layer chromatograms. Journal of Lipid Research $5,126-127$.

ESTRABROOK, R. W. (1967). Mitochondrial respiratory control and the polarographic measurement of ADP :O ratios. Methods in Enzymology 10, 41-47.

Folch, J., Lees, M. \& Sloane-Stanley, G. H. (1957). A simple method for the isolation and purification of total lipids from animal tissues. Journal of Biological Chemistry 226, 497-509.

Ghannoum, M. A., Janini, G., Khamis, L. \& RADWAN, S. S. (1986a). Dimorphism-associated variations in the lipid composition of Candida albicans. Journal of General Microbiology 132, 2367-2375.

Ghannoum, M. A., Thomson, M., Bowman, W. \& AL-KhaliL, S. (1986b). Mode of action of the antimicrobial compound 5-bromo-5-nitro-1,3-dioxane (Bronidox). Folia microbiologica 31, 19-31.

KabELIK, J. C. (1970). Antimikrobialle Eigenschaften des Knoblauchs. Pharmazie 25, 266-270. (In Chemical Abstracts 73, 11795r, 1970.)

Kates, M. \& Paradis, M. (1973). Phospholipid desaturation in Candida lipolytica as a function of temperature and growth. Canadian Journal of Biochemistry 51, 184-197.

KuNITZ, M. (1947). Crystalline soybean trypsin inhibitor. II. Journal of General Physiology 30, 291.

Maccacaro, G. A. (1961). The assessment of the interaction between antibacterial drugs. Progress in Industrial Microbiology 3, 173-210.

Mangold, H. K. \& Malins, D. C. (1960). Fractionation of fats, oils and waxes on thin layers of silicic acid. Journal of the American Oil Chemists' Society 37, 383-385. 
Moore, G. S. \& Atkins, R. D. (1977). The fungicidal and fungistatic effects of an aqueous garlic extract on medically important yeast-like fungi. Mycologia 69 , 341-348.

Nichols, B. W. (1964). Separation of plant phospholipids and glycolipids. In New Biochemical Separations. Edited by A. T. James \& I. J. Morris. London: Van Nostrand.

Parks, L. W., Mclean-Bowen, C., Taylor, F. R. \& Hough, S. (1978). Sterols in yeast subcellular fractions. Lipids 13, 730-735.

Prasad, G. \& Sharma, V. D. (1980). Efficacy of garlic (Allium sativum) treatment against experimental candidiasis in chicks. British Veterinary Journal 136, 448-451.

Prasad, G., Sharma, V. D. \& Kumar, A. (1982). Efficacy of garlic (Allium sativum L.) therapy against experimental dermatophytosis in rabbits. Indian Journal of Medical Research 75, 465-467.

RACKER, E. (1955). Alcohol dehydrogenase from baker's yeast. Methods in Enzymology 1, 500.
Radwan, S. S. (1978). Coupling of two-dimensional thin-layer chromatography with gas chromatography for the quantitative analysis of lipid classes and their constituent fatty acids. Journal of Chromatographic Science 16, 538-542.

Siakotos, A. N. \& Rouser, G. (1965). Analytical separation of nonlipid water soluble substances and gangliosides from other lipids by dextran gel column chromatography. Journal of the American Oil Chemists' Society 42, 913-919.

Stahl, E. (1962). Dunnschicht Chromatographie, 2nd edn, pp. 253-298. Berlin: Springer.

TYNECKA, A. \& Gos, Z. (1973). The inhibitory action of garlic (Allium sativum L.) on growth and respiration of some microorganisms. Acta microbiologica polonica 5B , 51-62.

WEETE, J. D. (1980). Lipid Biochemistry of Fungi and Other Organisms. New York: Plenum Press. 